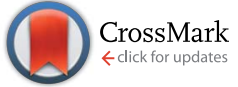

Cite this: RSC Adv., 2017, 7, 13312

Received 16th January 2017

Accepted 12th February 2017

DOI: $10.1039 / c 7 r a 00647 \mathrm{k}$

rsc.li/rsc-advances

\section{Synthesis of stable cationic waterborne polyurethane with a high solid content: insight from simulation to experiment}

\begin{abstract}
Meng Li, ${ }^{\star a}$ Fen Liu, ${ }^{a}$ Yu Li ${ }^{a}$ and Xihuai Qiang*b
Stable cationic waterborne polyurethanes (CWPUs) with a high solid content (HSC) were synthesized via the combination of cationic ionic and nonionic segments (polyoxyethylene alkyl amine, PAE). The process was based on an iterative strategy to design the cationic groups in soft segments and the chain terminal of polyurethanes (terminal ions) together with the determination of the optimal bimodal particle size distribution (PSD). The effects of the polymerization degree of poly(ethylene glycol) groups (PEG-g) in PAE and its interaction with the hydrophilic groups $N$-methyl diethanolamine (MDEA) in polyurethane were studied. It was found that the terminal ions resulted in a much finer dispersion, better dispersion stability, smaller particle size and lower viscosity. Moreover, the highest solid content (52.18\%) of CWPU was obtained by the incorporation of PAE and a low terminal ions content of $2.5 \%$, which had a bimodal particle size distribution. The increasing length of PEG-g was also found to enhance the thermal stability and render a better mechanical stability for the polyurethane films as the increasing PEG-g length may weaken the hydrogen bonding and reduce the extent of phase separation. The experimental results were further compared with molecular dynamic simulation results, which verified that the specific molecular structure of this WPU ensured its excellent properties. The static structure and dynamic properties obtained strongly supported the experimental observations reported on the morphology and thermal and mechanical properties of these polyurethanes.
\end{abstract}

\section{Introduction}

Owing to strict environmental and legislative pressures, the use of conventional solvent-based polyurethanes has steadily been discouraged. As a type of multi-functional environmentally friendly material, waterborne polyurethanes (WPUs) with excellent properties can be used in a wide range of fields such as coatings, adhesives, inks, biological materials, building materials, automotive, textiles and other industries. ${ }^{1-5}$ From the viewpoint of materials technology, the important properties are the static and dynamic mechanical properties, acoustic, optical and electrical properties, as well as corrosion resistance, chemical performance, adhesive properties and biological performance of PU plastic. ${ }^{6-8}$ However, there are still many disadvantages reported for WPUs developed in their present state. For instance, compared to conventional solvent-based polyurethanes, WPUs exhibit a slower drying rate due to the high latent heat of evaporation of water. Besides, a longer drying time and higher energy consumption is usually required

${ }^{a}$ Department of Applied Chemistry, School of Science, Xi'an Jiaotong University, Xi'an 710049, People's Republic of China. E-mail: limeng0721@stu.xjtu.edu.cn ${ }^{b}$ College of Bioresources Chemical and Materials Engineering, Shaanxi University of Science \& Technology, Xi'an 710021, People's Republic of China. E-mail: qiangxihuai@163.com for WPUs to achieve enough mechanical strength, due to the linear hydrophilic groups. ${ }^{6}$ This is not beneficial to meet the time efficiency and economic benefit requirements. Hence, research nowadays is mainly focused on the preparation of WPUs with a high solid content, which is of growing interest both in the field of scientific research and in industrial applications. ${ }^{9-13}$ As an important category of WPUs, cationic waterborne polyurethanes show excellent adhesion to anionicsubstrates, such as glass and leather; ${ }^{\mathbf{1 4}}$ however, products made with CWPUs are relatively rare to date. Nonionic hydrophilic monomers are also employed to synthesize WPUs. However, as far as we know, in the published work, the solid content of waterborne polyurethanes mainly ranges from 20 to $40 \mathrm{wt} \%$, and the synthesis of WPUs with a solid content higher than $50 \%$ is rarely reported in the literature, in which most of the published work is dominated by the synthesis of anionic WPUs.

The critical point to obtain WPUs with a high solid content is to effectively control the latex viscosity. The viscosity of a latex increases extremely rapidly with the augmentation of the solid content, especially above the upper limit of the solid content, ${ }^{15,16}$ since the particles are so crowded that the interactions between neighbouring particles are strong. ${ }^{17}$ Particle size distribution (PSD) is an important parameter in determining the relationship between the solid content and 
viscosity, ${ }^{18,19}$ and one of the key points to obtaining a high solid content with low viscosity ( $\mathrm{HSC} / \mathrm{LV}$ ) is to control the particle size and its distribution. Generally, it is possible to increase the upper limit of solid content of WPUs with a multimodal PSD, since the small particles are able to fit into the interstices between large particles, thus weakening the particles' interactions. Furthermore, if the difference between the particle diameters and the volume percentage is located in a reasonable range, small particles could efficiently pack into the voids among the large particles, thus increasing the maximum packing factor of the particles..$^{\mathbf{2 0 1} 21}$

Another method to decrease the viscosity of WPUs is to reduce the dosage of ionic monomers in polyurethane, which can suppress the swelling of latex particles ${ }^{22}$ caused by the electric double layer, along with the electroviscous effect of latex particles. So reduction of the dosage of ionic monomers in polyurethane can increase the solid content. Lee and $\mathrm{Kim}^{23}$ designed a WPU with ionic groups merely in soft segments and chain terminals, which made the hydrophilic groups easily enter the surface of particles, and thus a solid content up to $45 \%$ was achieved with the dosage of DMPA down to $2 \%$. However, the decrease in ionic groups possibly will lead to poor latex stability. Hou and his co-workers ${ }^{11}$ synthesized a WPU with a high solid content via the combination of ionic and nonionic monomers. Although one of the WPU's solid content reached a maximum value of $52 \%$, this work only focused on PEG systems, where the products are anionic polyurethanes. Other relative research work reported by Y. Chen and Y. L. Chen verified that a minimum content of $-\mathrm{COOH}\left(0.178 \mathrm{mmol} \mathrm{g}^{-1}\right.$ or $2.4 \%$ DMPA) is required to form stable dispersions. ${ }^{24}$ All the existing research indicates that employing ionic monomers alone has a limited ability for developing high solid content WPUs.

As to the synthesis of WPUs, the combination of ionic and nonionic monomers was employed to obtain finer particles than possible just using ionic monomers alone, ${ }^{25}$ which implies that the combination has a positive effect on the dispersion and stability properties of WPUs. In these processes, the ionic centres were incorporated as chain extenders and were located in the hard segments. Consequently, the mobility of the ionic segments was very much limited by the rigidity of the hard segments, and the ionic groups were not well exposed to the particle surfaces, which ensured more ionic groups to produce a stable dispersion. Besides, the connection relationships of anionic and nonionic monomers or the position of those hydrophilic groups in polyurethane should also have an influence on the dispersion and stability properties of WPUs. ${ }^{26}$ Namely, the combination of ionic and nonionic monomers, normally containing oxyethyl segments, has a synergistic effect on WPUs, leading to fine particle sizes and a stable dispersion with low hydrophilic groups.

Nowadays, the structural design and property characterization of WPUs are mainly based on laboratory trial and error experiments, which is necessary but time-consuming and not efficient. In the case of cationic WPUs, since the polymerization process is much more violent than that of anionic one, and the emulsifying capacity of cationic hydrophilic monomers is lower than that of anionic monomers, detailed experimental as well as theoretical studies on the structure-property relationship of CWPUs have not been widely reported. Computer simulation in turn can provide an attractive complement or substitute tool to support the efforts involved in the synthesis and characterization of new products. ${ }^{27-29}$ Moreover, molecular simulations have played an increasingly important role in materials modelling and subsequent technology development, as they can reveal the microscopic pictures of underlying mechanisms that are otherwise experimentally inaccessible or difficult to obtain. ${ }^{30,31}$ In addition, molecular simulations can also provide an insight into the microcosmic structural changes ultimately responsible for the macrocosmic behaviour. Raghu et al. ${ }^{7}$ investigated the effects of hard segments in the polyurethane chain on the cohesive energy density, the surface properties and the solubility parameter values by using MD simulations and an experimental method, and they reported that the simulation results showed good agreement with the experimental data. Rahmati and his co-workers ${ }^{27}$ investigated the effect of the degree of polyurethane polymerization on the structural, physical and separation properties via the use of grand canonical Monte Carlo and molecular dynamic methods.

Considering the lack of studies in the existing literature, in this study reported here, we combined atomistic simulations and laboratory experiments to explore the synergistic effect on the combination of cation ionic (MDEA) and nonionic monomers (PAE) in polyurethane, and designed the ionic groups in the terminal of the main chain polyurethane as well as in the hard and soft segments. The effect of MDEA and PEG-g in PAE on the dispersion size, viscosity and stability of latex were then analyzed. The thermal and mechanical properties of the derived films were also studied. The main objective of the work was to obtain a further understanding of the key factors important to synthesize CWPUs with a high solid content, as well to reveal the relations between the micro-simulation and macroexperiments. Meanwhile, this strategy could provide a novel synthetic scheme to CWPUs with a high solid content.

\section{Experimental}

\section{Main materials}

Isophorone diisocyanate (IPDI, Aladdin) and 2,4-tolylene diisocyanate (TDI, Aladdin) were purified by distillation under a reduced pressure of $1330 \mathrm{~Pa}$ at $120{ }^{\circ} \mathrm{C}$. Poly(neopentylglycol adipate) (PNGA) $\left(M_{\mathrm{n}}=1000\right.$, Shengfang Co., China) and $N$ methyl diethanolamine (MDEA, Aladdin) were both dried in an oven at $120{ }^{\circ} \mathrm{C}$ for $2 \mathrm{~h}$. Acetone was distilled and kept on a $4 \AA$ molecular sieve before use. Poly(oxyethylene alkyl amine) (PAE, PAE1205, PAE1210, PAE1220, PAE1230, Shengfang Co., China), di- $n$-butyltin dilaurate (DBTDL) and acetic acid were used as received. Acetic acid, acetone and DBTDL were all products of Aladdin Co.

\section{Molecular design and synthesis of the CWPUs}

The first step in the synthesis of the WPUs was to introduce the cationic and nonionic segment into the soft segment (SS), 
which was to be used to produce the $\mathrm{OH}$-terminated soft segments from IPDI and PAE. The second step was to locate the cationic groups in the chain termini and to build up the NCOterminated hard segments (HSs) through two processes. First, prepolymer I was synthesized based on TDI and PNGA. Then, MDEA was reacted with prepolymer I to build up the HS. Finally, the $\mathrm{OH}$-terminated SS was added to the reactor and reacted with NCO-terminated $\mathrm{HS}$ to obtain the cationic polyurethanes (Scheme 1).

A $250 \mathrm{~mL}$ round-bottomed, four-necked flask equipped with a nitrogen inlet, a condenser with a drying tube, a mechanical stirrer and a thermometer were used for the reaction. The synthesis of CWPU (Scheme 1) was catalyzed by DBTDL (0.03\% based on the total solid content). The reactions were implemented at $80{ }^{\circ} \mathrm{C}$ until the theoretical NCO values were obtained, as determined by the dibutylamine titration method (ASTM D2572-97(2010)). Acetone was added at the same time to reduce the viscosity. Then, acetic acid as a neutralizing agent was not added into the reaction until the mixture was slowly cooled to $40{ }^{\circ} \mathrm{C}$. The neutralization reaction proceeded at the same temperature for $30 \mathrm{~min}$. Finally, distilled water was added to the mixture (based on 50\% solid) with agitation at high shearing rates $(2000 \mathrm{rpm})$ to emulsify the solution. The CWPU was obtained after the removal of acetone from the emulsion at $50{ }^{\circ} \mathrm{C}$ by rotary vacuum evaporation under reduced pressure. The formulations used to prepare the CWPU are given in Table 1.

\section{Characterization}

A latex film was prepared for further testing by casting the emulsion on a Teflon plate and drying at ambient temperature for 7 days and then in a vacuum system at $50{ }^{\circ} \mathrm{C}$ for 2 days.
The Fourier transform infrared (FTIR) spectrum was recorded with a Perkin-Elmer Spectrum 100 FTIR spectrometer in the range $4000-500 \mathrm{~cm}^{-1}$ using a thin film prepared by casting a dilute DMF solution of the latex onto $\mathrm{KBr}$ flake and then evaporating DMF by heating under the infrared lamp.

The average particle sizes of the polyurethane dispersions were determined by a Zetasizer Nano-s (Malvern Instruments). Approximately $0.1 \mathrm{~mL}$ of the dispersion was diluted with $3 \mathrm{~mL}$ deionized water before the measurements. All the samples were measured at a temperature of $25{ }^{\circ} \mathrm{C}$.

Transmission electron microscopy (TEM) images were obtained from a HITACHI-H7650 Microscope with an accelerating voltage of $80 \mathrm{kV}$, with the samples stained by $0.2 \mathrm{wt} \%$ phosphotungstic acid hydrate before observation.

Thermogravimetric analysis (TGA) was performed using a TGA Q5000 thermogravimetric analyzer (TA Instruments). The samples were placed in an alumina crucible and heated at $10{ }^{\circ} \mathrm{C}$ $\min ^{-1}$ from $30{ }^{\circ} \mathrm{C}$ to $500{ }^{\circ} \mathrm{C}$ under a $\mathrm{N}_{2}$ atmosphere, where the flow rate of $\mathrm{N}_{2}$ was $30 \mathrm{~mL} \mathrm{~min}^{-1}$.

The DSC experiments were carried out in a DSC-200 instrument (NET-ZSCH, Germany). An aluminium pan containing 10$15 \mathrm{mg}$ of sample was heated from $-70{ }^{\circ} \mathrm{C}$ to $100{ }^{\circ} \mathrm{C}$ under a nitrogen atmosphere (flow rate: $40 \mathrm{~mL} \mathrm{~min}^{-1}$ ). The heating rate was $10{ }^{\circ} \mathrm{C} \mathrm{min}^{-1}$. The first heating run was carried out to remove the thermal history of the samples. From the second heating run, the DSC curve of the sample was obtained.

The viscosities of the CWPU dispersion were measured in a Brookfield digital viscometer (Model DVII). Measurements were carried out at $25{ }^{\circ} \mathrm{C}$ using spindle No. 1 at $30 \mathrm{rpm}$.

The tensile properties of the cast films were measured at room temperature using an Instron 5566 testing machine,

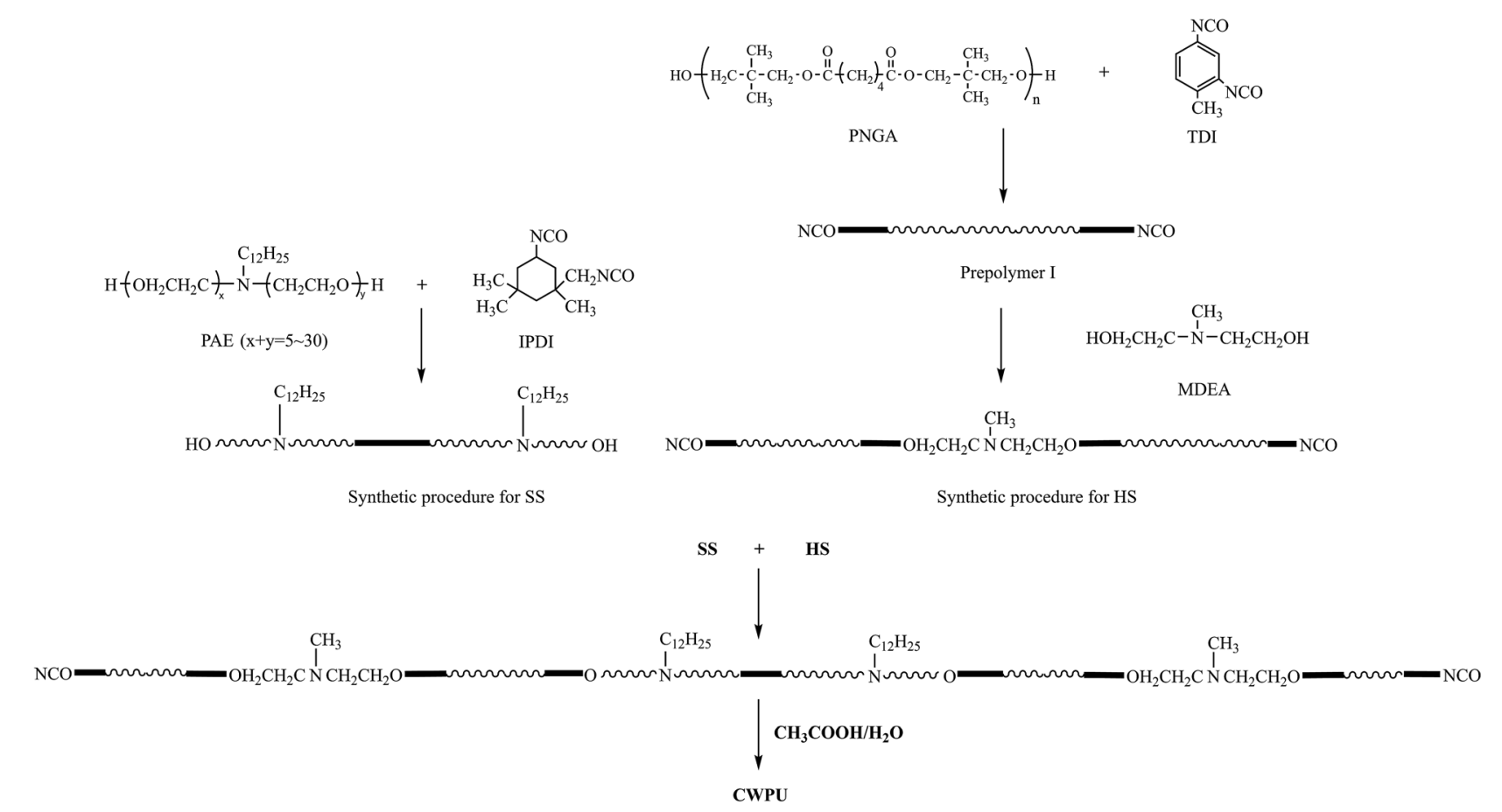

Scheme 1 Synthetic procedure for preparing the cationic waterborne polyurethane. 
Table 1 Basic formulations for synthesis of the WPU (the composition of HS and SS is in a molar ratio of $R=1.2$ in all the samples)

\begin{tabular}{|c|c|c|c|c|c|c|c|c|c|}
\hline Sample ${ }^{a}$ & \multicolumn{3}{|c|}{ Hard segment } & \multicolumn{2}{|c|}{ Soft segment } & $\mathrm{PEG}^{b}$ monomers & $\begin{array}{l}\text { Stability/6 } \\
\text { months }\end{array}$ & $\mathrm{MC}^{c}$ & $\mathrm{SC}^{d}$ \\
\hline $\mathrm{P} 10-15$ & 1.90 & 1.00 & 0.26 & 0.50 & 1.00 & PEG-g-400 & NS & 1.5 & 43.37 \\
\hline P20-15 & 1.95 & 1.00 & 0.32 & 0.50 & 1.00 & PEG-g-1000 & NS & 1.5 & 43.26 \\
\hline P30-15 & 2.00 & 1.00 & 0.38 & 0.50 & 1.00 & PEG-g-1500 & NS & 1.5 & 42.06 \\
\hline P20-25 & 2.15 & 1.00 & 0.55 & 0.50 & 1.00 & PEG-g-1000 & NS & 2.5 & 49.15 \\
\hline P30-25 & 2.25 & 1.00 & 0.65 & 0.50 & 1.00 & PEG-g-1500 & NS & 2.5 & 45.53 \\
\hline P05-35 & 2.20 & 1.00 & 0.58 & 0.50 & 1.00 & PEG-g-200 & NS & 3.5 & 49.57 \\
\hline P10-35 & 2.25 & 1.00 & 0.65 & 0.50 & 1.00 & PEG-g-400 & NS & 3.5 & 50.08 \\
\hline P20-35 & 2.40 & 1.00 & 0.79 & 0.50 & 1.00 & PEG-g-1000 & NS & 3.5 & 46.66 \\
\hline P30-35 & 2.55 & 1.00 & 0.93 & 0.50 & 1.00 & PEG-g-1500 & LS & 3.5 & 41.68 \\
\hline
\end{tabular}

${ }^{a}$ Sample code was named according to the content of PEG-g and MDEA; for example, P10-25 means containing 10 PEG-g in PAE and 2.5\% MDEA. ${ }^{b}$ The content of PEG-g in PAE approximate PEG monomers. ${ }^{c} \mathrm{MC}=$ MDEA content based on total weight of polymer. ${ }^{d} \mathrm{SC}=$ solid $^{c}$ content of CWPU. ${ }^{e} \mathrm{NS}=$ no sedimentation; $\mathrm{LS}=$ little sedimentation; $\mathrm{MS}=$ much sedimentation.

according to the ASTM D-412 specifications. A crosshead speed of $100 \mathrm{~mm} \mathrm{~min}^{-1}$ was used.

Stability of the CWPU: every day, $50 \mathrm{~mL}$ latex was placed in a glass bottle at room temperature to observe the condition of the latex, and it was recorded the number of days when lamination or precipitation had occurred.

The percentage of swelling for a particular film was determined by measuring its weight increase as a function of time using the equation:

$$
\% \text { swell }=\frac{W-W_{0}}{W_{0}} \times 100
$$

where $W_{0}$ is the weight of the dried film and $W$ is its weight after water absorption.

\section{Molecular dynamic simulations}

\section{Simulation detail}

Atomistic molecular dynamic simulations were conducted using the software package LAMMPS (Large-scale Atomic/ Molecular Massively Parallel Simulator $)^{32}$ and analysis was partially carried out using VMD. ${ }^{33}$ The simulations were carried out with the explicit-atom Dreiding ${ }^{34}$ force-field for the calculation. The simulation cells were cubic with periodic boundary conditions in all three dimensions. For all the samples, we first put one chain of each polymer in a cubic cell, and after minimizing the energy we replicated the cell 8 times, so there were 8 chains for each polymer in the new cell. The equations of motion were integrated with the velocity-Verlet integrator with a time step equal to 1 fs. ${ }^{35,36}$ Lennard-Jones and coulombic interactions had a cut-off value of $12.5 \AA$. Long-range coulombic interactions were computed using the $\mathrm{PPPM}^{37}$ method with the desired error in forces within $10^{-6}$ accuracy.
Considering the computational accuracy and expense, the model size was controlled at approximately a maximum of 12000 atoms in the models. Periodic boundary conditions were applied to the cubic simulation cells. For each system, all the chosen configurations were subject to a 10 circle thermal annealing from $300 \mathrm{~K}$ to $600 \mathrm{~K}$ and then back to $300 \mathrm{~K}$ with $50 \mathrm{~K}$ intervals. At each temperature, a 100 ps NPT ensemble was performed at constant pressure ( 1 bar) with a time step of $1 \mathrm{fs}$. A Nose thermostat and Berendsen ${ }^{38}$ barostat were used in all the simulations. At this situation, the last configuration was further subject to a 50000 step energy minimization, followed by annealing. Then the system was cooled down at intervals of 20 $\mathrm{K}$, followed by a $1 \mathrm{~ns}$ NPT simulation to obtain the final equilibrium density. Afterward, the 10 ns NPT and 5 ns NVT simulations were performed to collect the data. The atomic trajectory, which was recorded every picosecond, was suitable for the structural and equilibrium thermodynamic properties analysis. For the simulations, we used a 12 core machine CPUs Intel Xeon@CPU X5650@2.67 GHz.

\section{Dihedral scans}

To obtain the contour surfaces of torsion energy $v s$. the dihedral angles of $\mathrm{O}-\mathrm{C}-\mathrm{C}-\mathrm{O}$ and $\mathrm{C}-\mathrm{O}-\mathrm{C}-\mathrm{C}$ in the backbone, double dihedral angle scan calculations of the $\mathrm{C}-\mathrm{C}$ or $\mathrm{O}-\mathrm{C}$ groups attached to adjacent bonds were carried out with Gaussian 09 (ref. 39) at the B3LYP-D3/6-311G(d,p) level. ${ }^{40-42}$ 'D3' indicates the DFT-D3 dispersion correction method, ${ }^{43}$ which was used to ensure the precision of the non-bond interaction calculations. ${ }^{44}$

\section{Results and discussion}

\section{FTIR spectra of the CWPU}

The expected chain structure of the CWPU was confirmed by FTIR spectroscopy and is displayed in Fig. 1. The FTIR spectra of 


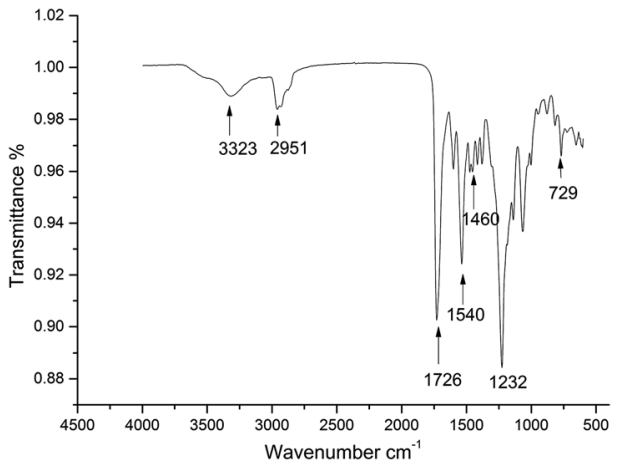

Fig. 1 IR spectrum of P10-25.

P10-25 (other spectra of the samples are not presented here for simplicity) showed the typical absorption peaks of polyurethane at $3323 \mathrm{~cm}^{-1}[v(\mathrm{NH})], 2850-2964 \mathrm{~cm}^{-1}\left[v\left(\mathrm{CH}_{2}\right)\right.$ and $\left.v\left(\mathrm{CH}_{3}\right)\right]$, and $1726 \mathrm{~cm}^{-1}[v(\mathrm{C}=\mathrm{O})]$. The typical NCO absorption peak at about $2273 \mathrm{~cm}^{-1}$ disappeared in P10-25, indicating that the NCO group had completely reacted. The peak at $1540 \mathrm{~cm}^{-1}$ was ascribed to the characteristic absorption peak of a quaternary ammonium salt. The characteristic absorption peaks of the bending vibration peak of a long alkyl chain and the rocking vibration peak of a long alkyl chain- $\left(\mathrm{CH}_{2}\right)_{n}-(n>4)$ were observed at 1460,1232 and $729 \mathrm{~cm}^{-1}$ in the WPU, respectively. This demonstrated that the PAE had been anchored onto the polyurethane chain. ${ }^{10,45}$

\section{Effect of the combination of PEG-g in PAE and MDEA on the latexes properties}

According to previous literature, highly stable WPUs with a high solid content can be obtained by some concrete influencing factors, such as the ionic group content, the position of cationic groups, the particle size distribution and the synergistic effect of cationic and nonionic groups. Those aspects were studied in the following section.

The effect of the PEG-g content in PAE on the synthesized CWPU is shown in Fig. 2. There is an obvious improvement on the dispersion and stability properties for the CWPUincorporated PAE. When using MDEA alone as a hydrophilic monomer, a stable latex can only be obtained with an MDEA

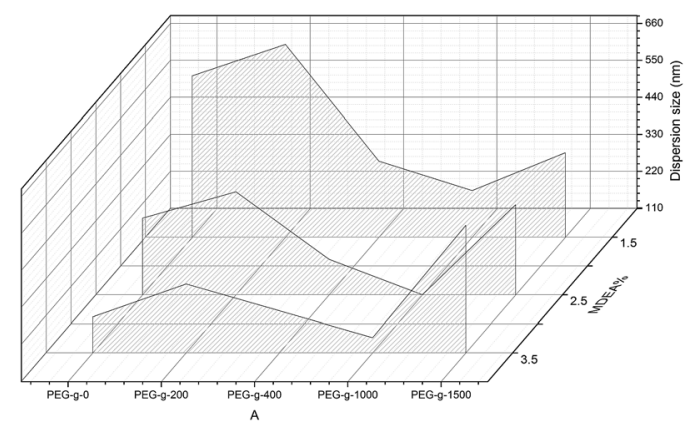

Fig. 2 The effect of PEG-g content in PAE on the average particle size of the CWPUs. content above $2.5 \%$. Those results are in accordance with previous results. For the samples incorporated with PEG-g-400 (or PEG-g-1000), all the samples had smaller particles size than the one incorporated with PEG-g-1500. However, all the samples incorporated with PEG-g-200 exhibit the largest sizes, indicating PEG-g-200 has little effect on improving the dispersion and stability of CWPU. So the effect of PEG-g is in the order of: PEG-g-400 $\approx$ PEG-g-1000 > PEG-g-1500 》 PEG-g-200.

\section{Synergistic effect of PEG-g and MDEA on the latexes properties}

When incorporating PAE into polyurethane, the hydrophilic $\left(-\mathrm{CH}_{2}-\mathrm{CH}_{2}-\mathrm{O}-\right)_{n}$ chains have the tendency to enter into the o/w interface and to decrease the $\sigma$ value of the interface, leading to a smaller average particle size (according to the Laplace equation, $\Delta P=2 \sigma / r)$. However, the movement of PEG-g is limited by its neighbouring hydrophobic groups, resulting in PEG-g-200, which can hardly enter the surface of the latex particles and so contributes little to the dispersion and stability properties. As the molecular mass increases $\left(M_{\mathrm{n}} \geq 400\right)$, the $\left(-\mathrm{CH}_{2}-\mathrm{CH}_{2}-\mathrm{O}-\right)_{n}$ has a stronger hydrophilicity than that of PEG-g-200 and thus can enter the surface of latex particles, and consequently finer dispersion and stability properties are obtained. Also, the effect of PEG-g-1500 is not as good as PEG-g-400 or PEG-g-1000 (as illustrated by Table 2), which is probably due to insufficient presence of PEG-g-1500 in the interfacial film, which is mainly embedded into water to form a thick hydrated layer with long hydrophilic $\left(-\mathrm{CH}_{2}-\mathrm{CH}_{2}-\mathrm{O}-\right)_{n}$ segments, and then the effect of the decreasing $\sigma$ is weakened (Fig. 3).

Meanwhile, the particle size in the terminal ions was much smaller than that in the hard ions. This indicates that the concentration of ionic groups at the surface with the terminal chain is much higher than that with the hard chain. This can be explained by considering the chain rigidity of the hard segments, the chain flexibility of the soft segments, the high mobility and the low free energy of the chain ends. If the conformation change needs less energy, more ionic groups will be exposed to the surfaces during the dispersion. This leads to smaller particles with greater dispersion stability.

As to the samples containing PEG-g-400, the particle sizes decreased sharply with increasing the hydrophilic $\left(-\mathrm{CH}_{2}-\mathrm{CH}_{2}-\right.$ $\mathrm{O}-)_{n}$ groups entering the $\mathrm{o} / \mathrm{w}$ interface and the decreasing $\sigma$, whereas the particle sizes of the samples incorporated with PEG-g-1500 increased abruptly (as illustrated in Table 2 and Fig. 4), and the latex then became viscous with the same water addition. The results further prove the assumption that the long hydrophilic chains of PEG-g-1500 may form a thicker hydrated layer, which is not beneficial for decreasing the particle size, regardless of its role in decreasing $\sigma$.

Moreover, it was found that the change of particle size showed a different trend in the case of PEG-g combined with MDEA compared to using PEG-g alone as a hydrophilic monomer (nonionic WPU), where in the latter case the higher molecular mass of PEG-g resulted in smaller particle sizes of the latexes. Those results indicated that there was a synergistic effect between PEG-g and MDEA, which allows the hydrophilic 
Table 2 Basic properties of the latexes and derived films

\begin{tabular}{lllll}
\hline Series & Dispersion size $(\mathrm{nm})$ & Viscosity $(\mathrm{mPa} \mathrm{s})$ & Tensile strength/Mpa & Breaking elongation/\% \\
\hline P05-15 & 683.3 & 228 & - & - \\
P10-15 & 336.2 & 200 & 18.85 & 685 \\
P20-15 & 248.5 & 112 & 17.57 & 733 \\
P30-15 & 361.4 & 520 & 16.33 & 764 \\
P05-25 & 416.3 & 609 & 23.73 & 637 \\
P10-25 & 214.7 & 626 & 20.17 & 677 \\
P20-25 & 108.6 & 517 & 18.26 & 717 \\
P30-25 & 378.2 & 870 & 17.57 & 755 \\
P05-35 & 312.9 & 976 & 24.71 & 629 \\
P10-35 & 233.3 & 510 & 22.91 & 661 \\
P20-35 & 153.4 & 480 & 19.56 & 703 \\
P30-35 & 488.5 & 3770 & 18.82 & 733 \\
P00-15 & 589.6 & 272 & - & \\
P00-25 & 337.8 & 708 & 26.01 & \\
P00-35 & 215.6 & 950 & 27.85 & 607
\end{tabular}

(a)

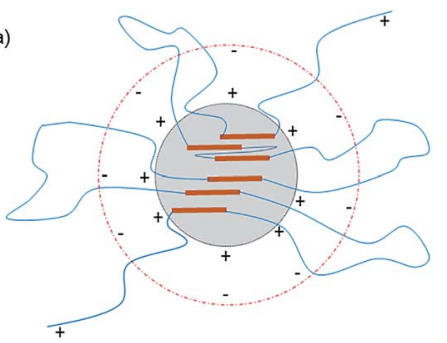

(b)

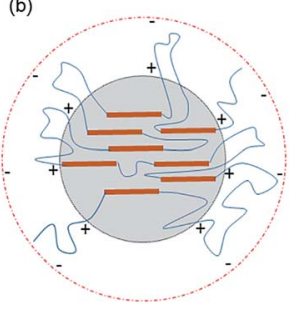

Fig. 3 Schematic of the latex particles incorporated with PEG-g: (a) incorporated with PEG-g-400 and (b) incorporated with PEG-g-1500.

groups in the CWPU to more easily enter into the o/w interface, resulting in better dispersion and stability.

\section{Effect of PSD on the latexes properties}

By optimizing the obvious synergistic effect of PEG-g with MDEA on CWPU, latexes with the best stability were obtained.

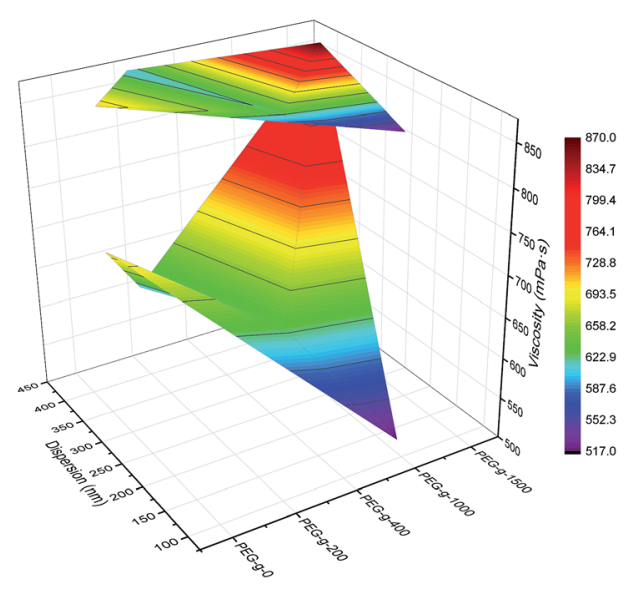

Fig. 4 Synergistic effect of PEG-g and MDEA on particle size and viscosity of the CWPU (only $2.5 \%$ MDEA shown here for ease of visualization).
Since the effects of PEG-g-400 and PEG-g-1000 are better than that of PEG-g-1500, we chose the system of CWPU with the dosage of MDEA as $2.5 \%$ (e.g. P05-25, P10-25, P20-25, P30-25) as representatives for the further experiments and analysis in the following section.

As shown in Fig. 5 and Table 2, it is interesting to find that P05-25 and P10-25 exhibit a bimodal particle size distribution while P00-25 and P30-25 showed a unimodal particle size distribution. From P05-25 to P20-25, it can be seen in the particle size distribution graphs that two peaks of the samples become closer and finally emerge into one peak in P30-25.

This phenomenon can be explained by the increment of PEG-g in the CWPU, resulting in the difference in the hydrophilicity of CWPU diminishing gradually and the average
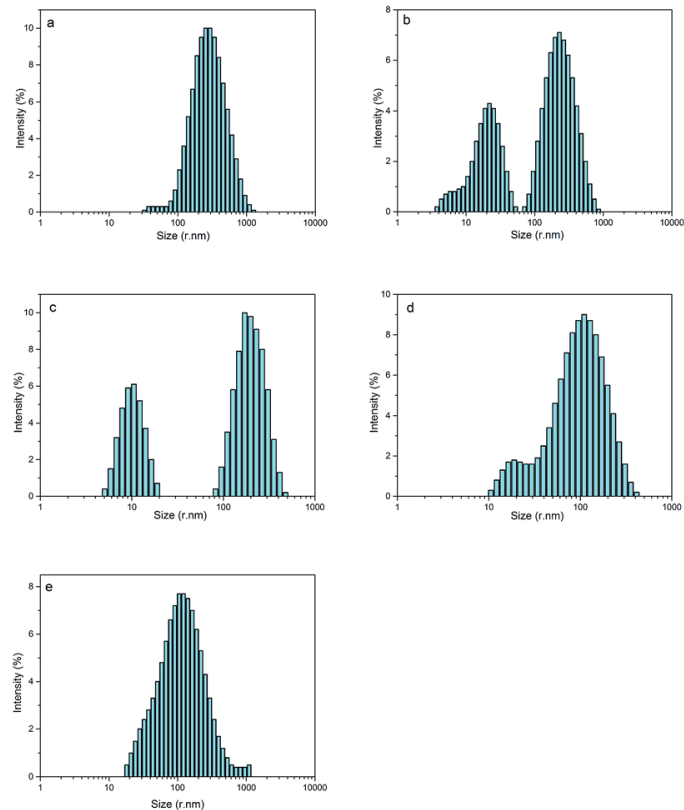

Fig. 5 The particle size distribution of CWPU, (a) P00-25; (b) P05-25; (c) P10-25; (d) P20-25 and (e) P30-25. 
particle sizes tending to be close. As a matter of fact, the viscosity increased sharply from P20-25 to P30-25, and all samples in the present study showed the same trend. According to the research on traditional emulsions by Greenwood, small particles were able to fit into the packs among large particles when the diameter ratio of large particles to small particles was more than 5.67 (ref. 20) (Fig. 6). As shown in Fig. 5, P20-25 with the diameter ratio of 5.1 presented a relatively high viscosity, which can be explained by the fact that many of the small particles are not actually small enough to fit into the interstices among the large particles, thus decreasing the packing efficiency. However, the viscosity of P05-25 with the diameter ratio of 12.6 was higher than P10-25 with the diameter ratio of 7.2, indicating that the packing density decreased when the diameter ratio was too large. Therefore, a particle diameter ratio of 7.2 and a reasonable bimodal PSD are appropriate to raise the up limit of the solid content for the CWPU.

\section{Particle morphology of the CWPU}

Fig. 7 shows the TEM images of P00-25 and P10-25. Both P00-25 and P10-25 contain globular particles, with P00-25 exhibiting a unimodal PSD and particle sizes around $600 \mathrm{~nm}$, whereas P1025 presented a bimodal PSD, with larger particles of 200$500 \mathrm{~nm}$ and smaller particles around $40 \mathrm{~nm}$. The particle sizes and the diameter ratio of large particles to small particles are in good accordance with the above data.

\section{Effect of the combination of PEG-g and MDEA on the film properties}

Thermal properties. The DSC curves corresponding to the second heating run of the CWPUs are shown in Fig. 8, and the values of the peaks are summarized in Table 3. Step transitions to the endothermic side appear in all the curves around $-50{ }^{\circ} \mathrm{C}$, corresponding to the glass transition of the soft segments $\left(T_{\mathrm{gs}}\right)$. Among these, the $T_{\mathrm{gs}}$ of P00-25 (without PAE) is higher than that of the other samples, probably due to the incorporation of $\left(-\mathrm{CH}_{2}-\mathrm{CH}_{2}-\mathrm{O}-\right)_{n}$ chains, which have a stronger movement ability and can dissolve in soft segments, making the $T_{\mathrm{gs}}$ shift to lower temperature. Besides, the $T_{\mathrm{gs}}$ of the samples incorporated with P05-25 are higher than that of the samples with P10-25 and P30-25, as shorter PEG-g chains can induce sufficient phase separation. A broad glass transition temperature centred at $25{ }^{\circ} \mathrm{C}$ to $41.1^{\circ} \mathrm{C}$ was seen in particular samples, which in the range of $20-100{ }^{\circ} \mathrm{C}$ can be assigned to the $T_{\text {gh }}$ of the hard segment of the urethane group, like the reported $T_{\text {gh }}$ for
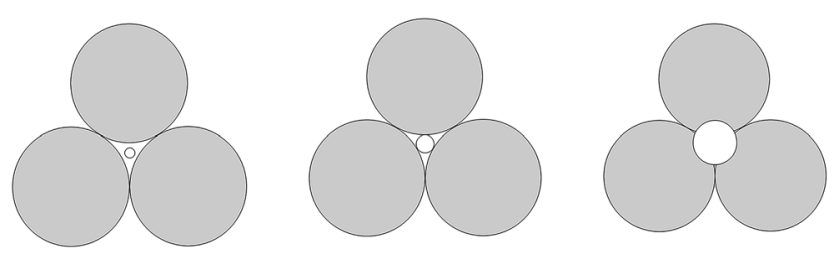

Fig. 6 A two-dimensional schematic showing the effect of the size of the smaller particles trying to pack into the pore among larger particles.

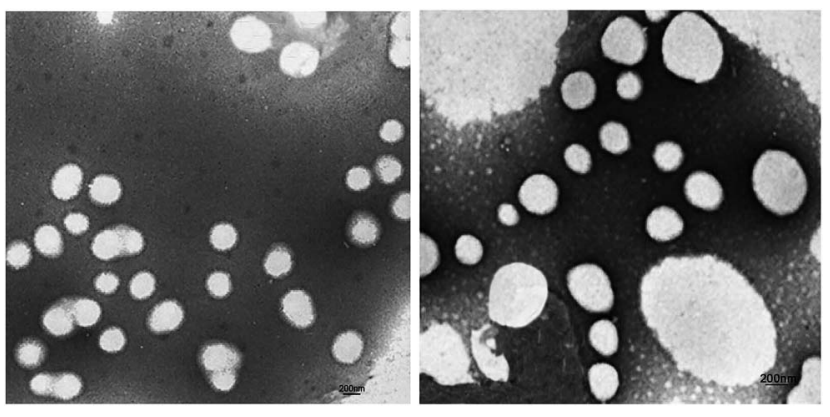

Fig. 7 TEM image of CWPU; P00-25 (left), P10-25 (right).

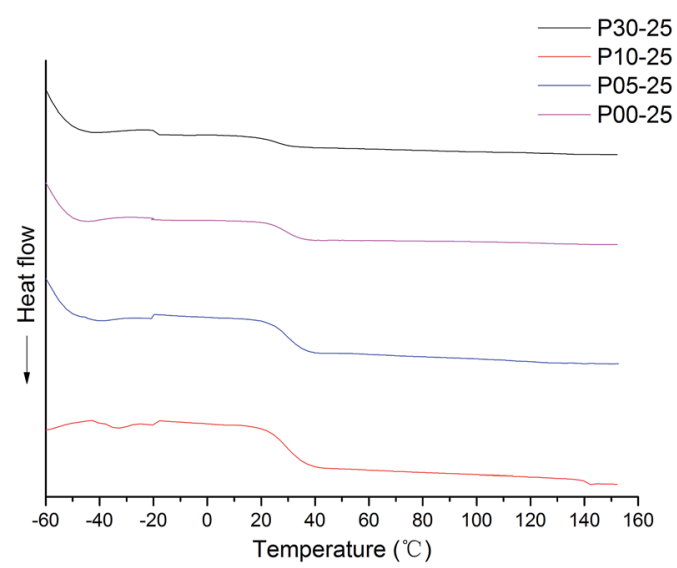

Fig. 8 DSC curves of different CWPUs.

urethane. ${ }^{46}$ It is worth noting that, with a similar $T_{\mathrm{gs}}$, with increasing the length of the $\left(-\mathrm{CH}_{2}-\mathrm{CH}_{2}-\mathrm{O}-\right)_{n}$ chain, the $T_{\mathrm{gh}}$ and the hydrogen bonding interactions are reduced, and then there is not a sufficient phase separation.

The thermal stability of WPU was evaluated by TG analysis. The typical TG and DTG curves of CWPU are shown in Fig. 9. TG analysis gave information, not only about the thermal stability of the polyurethanes but also on their structure, as the differentiated degradation steps of the hard and soft segments can be detected. What is especially important is the initial degradation temperature, which is dependent on the thermal stability of the weakest point(s) within the polyurethane macromolecule, i.e. urethane bonds and ester bonds. It is known that the hard segments are more prone to thermal decomposition than the soft segments in polyurethane. The basic process that takes place during degradation is depolymerization, i.e. the decomposition of PU to its parent substances: diisocyanate and

Table $3 T_{\mathrm{g}}$ data of the different CWPUs

\begin{tabular}{llllll}
\hline Samples & $T_{\mathrm{gs}} /{ }^{\circ} \mathrm{C}$ & $T_{\mathrm{gh}} /{ }^{\circ} \mathrm{C}$ & $T_{5 \%} /{ }^{\circ} \mathrm{C}$ & $T_{10 \%} /{ }^{\circ} \mathrm{C}$ & $T_{50 \%} /{ }^{\circ} \mathrm{C}$ \\
\hline P00-25 & -40.3 & 32.2 & 139.34 & 182.60 & 297.85 \\
P05-25 & -52.2 & 30.2 & 149.98 & 208.14 & 325.27 \\
P10-25 & -54.8 & 28.1 & 157.58 & 212.53 & 330.01 \\
P30-25 & -55.3 & 24.7 & 177.15 & 220.56 & 361.81
\end{tabular}



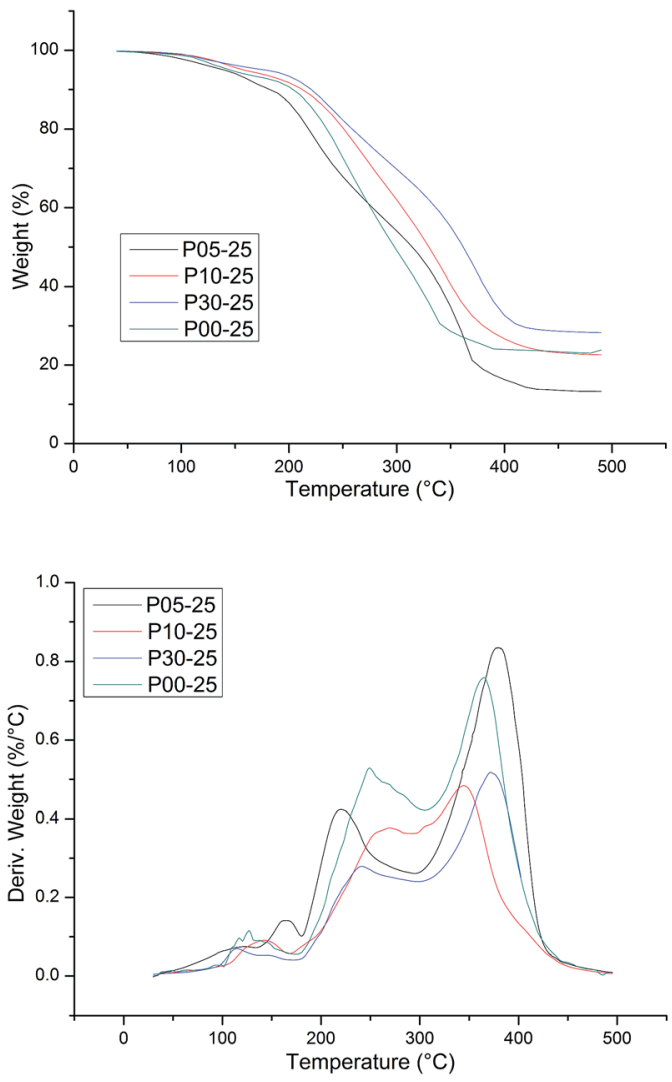

Fig. 9 TG and DTG curves of the different CWPUs.

polyols. The DTG curve of WPU presents a different degradation mechanism and indicates three stages of degradation. The first degradation at temperature ranges of $50-200{ }^{\circ} \mathrm{C}$ can be attributed to the volatilization of small molecular material remaining in the film. The second degradation at the temperature range of 250-350 ${ }^{\circ} \mathrm{C}$ mainly relates to the destruction of urethane groups. Finally, the maximum weight loss occurs within the range of $350-440{ }^{\circ} \mathrm{C}$ and most probably relates to the disruption reaction of ester bonds in polyester urethanes.

The thermal degradation temperatures of $5 \%$ weight loss $\left(T_{5 \%}\right), 10 \%$ weight loss $\left(T_{10 \%}\right)$ and $50 \%$ weight loss $\left(T_{50 \%}\right)$ are summarized in Table 3. As shown in Table 3, the higher the content of soft segments in a polymer is, the more stable the polymer is at elevated temperatures and the lower the initial rate of its degradation is. This phenomenon can be attributed to the length of PAE increasing, as it was shown that as the content of flexible segments in the polymer increases, the degree of phase separation decreases at the same time, and then there are lower hydrogen bonding interactions. The temperature of thermal resistance slightly increases in such cases. In addition, the presence of a side alkane groups in the CWPU reduces the potential for the formation of urethane-urethane hydrogen bonds, which makes it difficult for hard segments to agglomerate, i.e. their phase separation becomes hindered. ${ }^{45}$

Mechanical properties. As illustrated in Table 2, the increment of MDEA dosage causes an increase in tensile strength, while the elongation at break decreases (e.g. P10-15, P10-25 and
P10-35), which was attributed to the cationic ammonium group promoting electrostatic and hydrogen bonding interactions, resulting in better phase separation. The opposite results were obtained when increasing the content of PEG-g in PAE (e.g. P0525, P10-25, P20-25 and P30-25), i.e. the tensile strength decreased, while the elongation at break increased, which was mainly due to two factors. First, the better flexibility that was obtained from increasing the length of $\left(-\mathrm{CH}_{2}-\mathrm{CH}_{2}-\mathrm{O}-\right)_{n}$ chains caused a decrease in the hydrogen bonding interactions, which then reduced the interchain interactions in the polymer. Second, and what is especially important, there was a synergistic effect from the cationic ammonium group and PEG-g on the hydrogen bonding interactions, which led to improved phase separation and enhanced interchain interactions in the polymer.

\section{Molecular simulations}

Simulation model construction. The different amorphous cells were constructed based on a 'real model', for which we chose four samples as well as the representatives of CWPU described above. The samples of P00-25, P05-25, P10-25 and P30-25 were denoted as A, B, C and D (Fig. 10). In addition, models with different degrees of polymerization of PEG-g (DP = $2,3,4,5,6,8,10,15$ and 30) were also constructed. For simplicity, all the models ignored the molecular weight distribution and only the final structure (Scheme 1) was adopted for constructing the amorphous cells.

Glass transition temperature. The glass transition temperature is one of the most direct parameters that is often used to correlate micro-simulations with macro-experiments. ${ }^{47}$ Thus, the $T_{\mathrm{g}}$ values of the representative samples above were calculated through several heating/cooling cycles within the range of $100-400 \mathrm{~K}$. The glass transition can be reflected by the plots of density ( $\rho$, or the specific volume, $\left.V_{\mathrm{sp}}\right) v s$. temperature $(T)$, which are then used to locate the inflection points (i.e. the $T_{\mathrm{g}}$ values). As Fig. 11 shows, with PEG-g increasing, the $T_{g}$ decreases, and this tendency is consistent with the experimental results. In addition, the inflection plots of the curves become less obvious

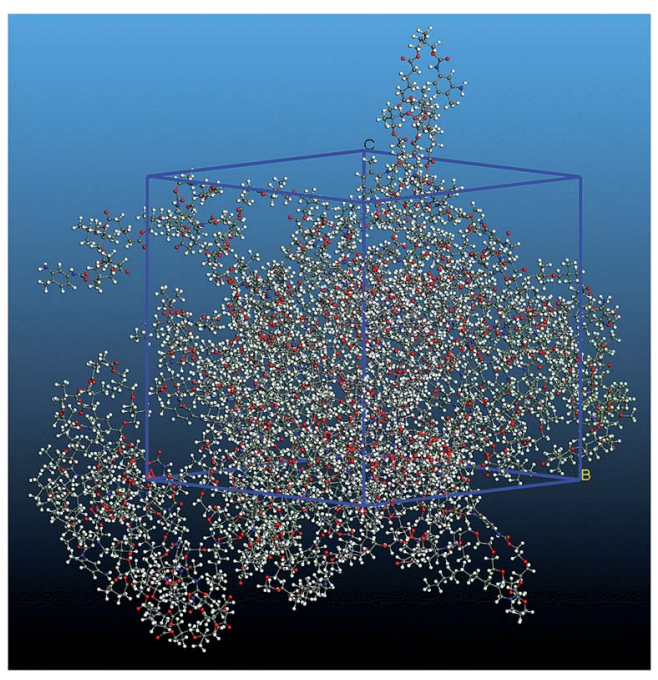

Fig. 10 Typical atomistic snapshots of a simulation cell of B. 

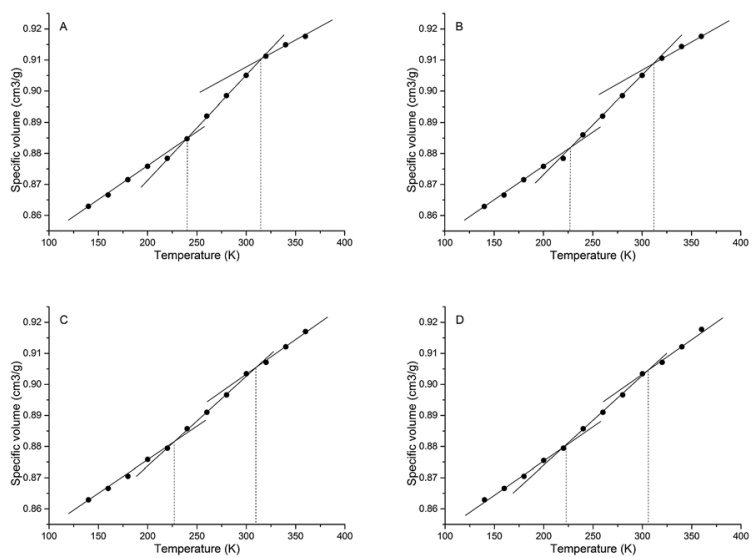

Fig. 11 Specific volumes of samples A, B, C and D as a function of temperature.

as the PEG-g content increases, meaning that longer PAE chains result in the hydrogen bonding decreasing and the degree of phase separation decreasing at the same time. However, the $T_{\mathrm{g}}$ values obtained from the $\rho-T$ curves for all the samples were approximately $10 \mathrm{~K}$ higher than the experimental $T_{\mathrm{g}}$ values. It is well-known that $T_{\mathrm{g}}$ depends on the thermal history and heating/ cooling rates during the heating/cooling cycles; ${ }^{48}$ thus, a large amount of structural disorder is frozen into the system over several tens of nanoseconds, especially for this type of longchain systems. Additionally, owing to the considerable differences in magnitude of the heating rate between the MD simulations $\left(20 \mathrm{~K} / 5 \times 10^{-11} \mathrm{~s}\right)$ and the DSC measurements $(10 \mathrm{~K} / 60$ $\mathrm{s})$, this finding is understandable for such routinely observed phenomena in molecular simulations. Furthermore, the computational and fitting errors and the significant difference in the composition between the simulation models and the real polymers will also contribute to the discrepancies between the simulated and experimental values ${ }^{49}$

Mean square displacements. To investigate the underlying motion of the molecules, the mean square displacements (MSDs) of the polyurethane chains within the amorphous cell were obtained from molecular dynamics simulations as following,

$$
\operatorname{MSD}(t)=\left\langle\left|r_{\mathrm{i}}(t)-r_{\mathrm{i}}(0)\right|^{2}\right\rangle
$$

where $r_{\mathrm{i}}(t)$ and $r_{\mathrm{i}}(0)$ are the position of atom $\mathrm{i}$ at time $t$ and 0 , respectively. The polymer chains in a solid matrix are in continuous motion and the MSD of a polymer is an important dynamic that reflects the mobility of the polymer chains. The MSDs of different samples are shown in Fig. 12, which usually reflects the polymer rigidity, i.e. a rigid polymer exhibits a lower MSD. The MSD for sample D shows a maximum amount, as expected since this polymer chain is relatively flexible. When increasing the length of PEG-g, the MSD of the CWPU is increased, which in turn decreases the chain rigidity. This result confirms the experimental conjecture that a longer PEG-g makes the polymer chain more flexible.

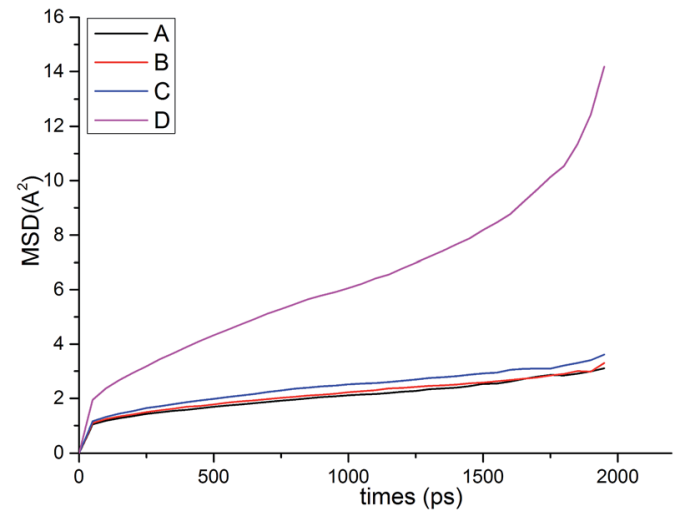

Fig. 12 The MSDs of the different samples.

Chain end-to-end distance and radius of gyration. In order to further verify the above results, the chain end-to-end distance and the radius of gyration of the CWPU were calculated as well and then used to describe spatial structure and dimensions of a polymer chain, respectively. The radius of gyration was calculated as follows:

$$
R_{\mathrm{g}}=\sqrt{\left(\frac{\sum_{\mathrm{i}}\left(\left|r_{\mathrm{i}}\right|\right)^{2} m_{\mathrm{i}}}{\sum_{\mathrm{i}} m_{\mathrm{i}}}\right)}
$$

where $m_{\mathrm{i}}$ is the mass of atom $\mathrm{i}$ and $r_{\mathrm{i}}$ is the position of atom $\mathrm{i}$ with respect to the mass centre of the molecule. The chain endto-end distance and the radius of gyration of the chains are shown in Table 4 . It can be seen clearly that the radius of gyration of polyurethane chains increases with the increase in the degree of polymerization (DP).

Fractional free volume. The free volume size and morphology are very important parameters to characterize the efficiency of chain packing and the amount of free space in a polymer matrix. Generally, positron annihilation lifetime spectroscopy (PALS) is the prevalent experimental method to determine the free volume probed by positron. ${ }^{50}$ Free volume characterization was analyzed by the Connolly surface method. The probe molecule was modelled by hard spheres with a radius of $1.4 \AA$ (the free volume obtained by a hard spherical probe; this value was also defined as the accessible surface area). ${ }^{51}$ As shown in Table 4, all the samples had a relatively small FFV and exhibited a tendency that this decreases with increasing the polymer chain length. Generally, a smaller value of FFV means a lower accessible surface area, i.e. a higher solid content, which is in accord with the experimental results. However, sample D had the lowest FFV, but it is not the one with the highest solids content. This abnormal phenomenon could be attributed to the hydrated layer.

Radial distribution functions. In order to further demonstrate the results above, the structural aspects of the CWPUs were examined using the radial distribution function (RDF). The atom-atom RDF proved to be very useful in illuminating the hydrogen bond interactions in bulk models. ${ }^{\mathbf{4 4}}$ There was 
Table 4 Molecular simulation data at $298 \mathrm{~K}$

\begin{tabular}{|c|c|c|c|c|c|c|c|c|}
\hline Samples ${ }^{a}$ & $T_{\mathrm{gs}} /{ }^{\circ} \mathrm{C}$ & $T_{\mathrm{gh}} /{ }^{\circ} \mathrm{C}$ & Free volume $/ \AA^{3}$ & Volume $/ \AA^{3}$ & $\mathrm{FFV} / \%$ & $R_{\mathrm{g}} / \AA$ & $R_{\text {ete }} / \AA ̊ ̊$ & $N_{\mathrm{HB}} / N_{\mathrm{O}}$ \\
\hline A & -33.2 & 41.1 & 13884.63 & 87975.15 & 15.78 & 31.38 & 16.23 & 0.092 \\
\hline B & -46.2 & 38.8 & 13841.84 & 91022.55 & 15.21 & 41.33 & 18.75 & 0.087 \\
\hline D & -50.5 & 32.9 & 17919.79 & 129540.96 & 13.83 & 58.40 & 23.20 & 0.061 \\
\hline
\end{tabular}

a presence of two classes of hydrogen bonds in this studied system (as illustrated in Scheme 2). ${ }^{31}$ However, we mainly analyzed the first type of hydrogen bond because of the difference in hydrogen bonds forming capability between the hard segments and soft segments. ${ }^{52}$

Fig. 13 shows the $\mathrm{O} \cdots \mathrm{N}$ RDFs in the samples at $298 \mathrm{~K}$. It can be seen that the first peak appearing in each RDF curve in the range from 1.8 to $2.1 \AA$ are generally lower in intensity with PEG$\mathrm{g}$ increasing, indicating that the hydrogen bonds decrease with the increasing PEG-g as expected. However, the second and third peaks increased with increasing PEG-g, which was probably attributed to the different chain conformation of PEG-g in PAE. Note that all sharp peaks at distances greater than $4 \AA$ are absent and the RDF tend to 1 , which is generally regarded as proof of the amorphous nature of a polymer system. ${ }^{.3}$ The $N_{\mathrm{HB}} /$ $N_{\mathrm{O}}$ ratio corresponds to the ratio of the total number of hydrogen bonds to the total number of oxygen atoms. As suggested by a previous study, ${ }^{54,55}$ a criterion of " $\mathrm{H} \cdots \mathrm{O}$ length $\leq 2.5$ $\AA$, C $-\mathrm{O} \cdots \mathrm{H}$ or $\mathrm{N}-\mathrm{H} \cdots \mathrm{O}$ bond angle $\geq 120^{\circ}$ " was adopted to count the total number of hydrogen bonds in each sample (Fig. 14). The calculated $N_{\mathrm{HB}} / N_{\mathrm{O}}$ ratios of the different samples are shown in Table 4 . It can be seen that the results are in accordance with the aforementioned results, i.e. the hydrogen bonds decrease with increasing PEG-g.

Torsion angle distribution. To examine the possible conjecture of the second and third peak of RDF as well as to carry out a detailed analysis of the spatial structure of polymer chain, we further estimated the conformational changes in the nanocomposites by calculating the distribution of the PEG-g in PAE chain dihedral angles. There are two types of dihedral angles in PEG-g, defined by (1) O-C-C-O and (2) C-O-C-C backbone atoms. A schematic representation of these atom sequences is shown on the left side of Fig. 15. Depending on the alignment of groups attached to adjacent bonds (in our case $\mathrm{C}-\mathrm{C}$ or $\mathrm{O}-\mathrm{C}$ ), we distinguished trans or gauche states.
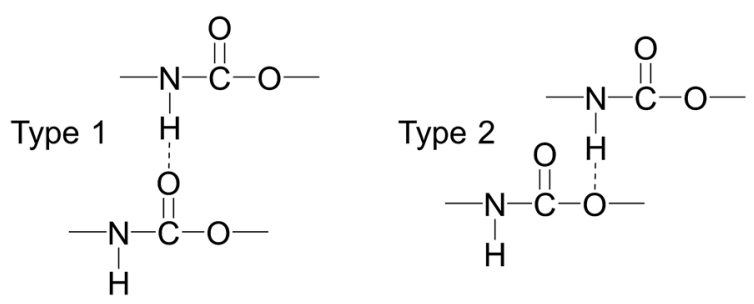

Scheme 2 Two possible forms of the hydrogen bonding between urethane compounds.

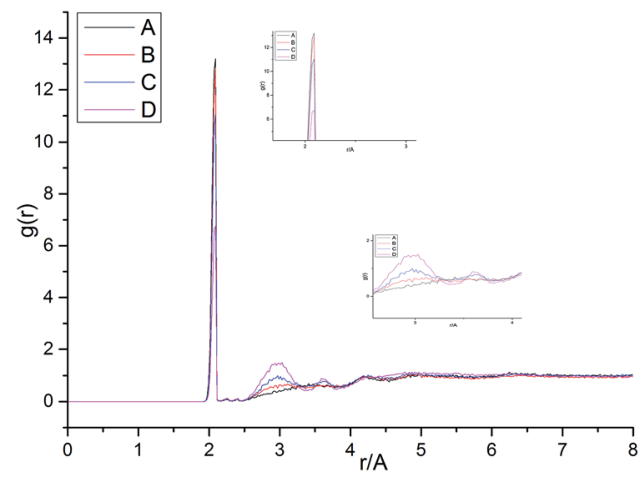

Fig. 13 The radial distribution functions of $\mathrm{O} \cdots \mathrm{N}$ at $298 \mathrm{~K}$.

As shown in Fig. 15, all the samples had a helical conformation because the OC-CO angles exhibited a large population of the gauche conformation at $\pm 70^{\circ}$, while the CC-OC angles have both gauche and trans states, which is in agreement with previous simulation studies and experimental results. ${ }^{56,57}$ Thus, the flexibility of the chains is related to the conformation structure of PEG-g in PAE. Chains with an ordered, all-trans
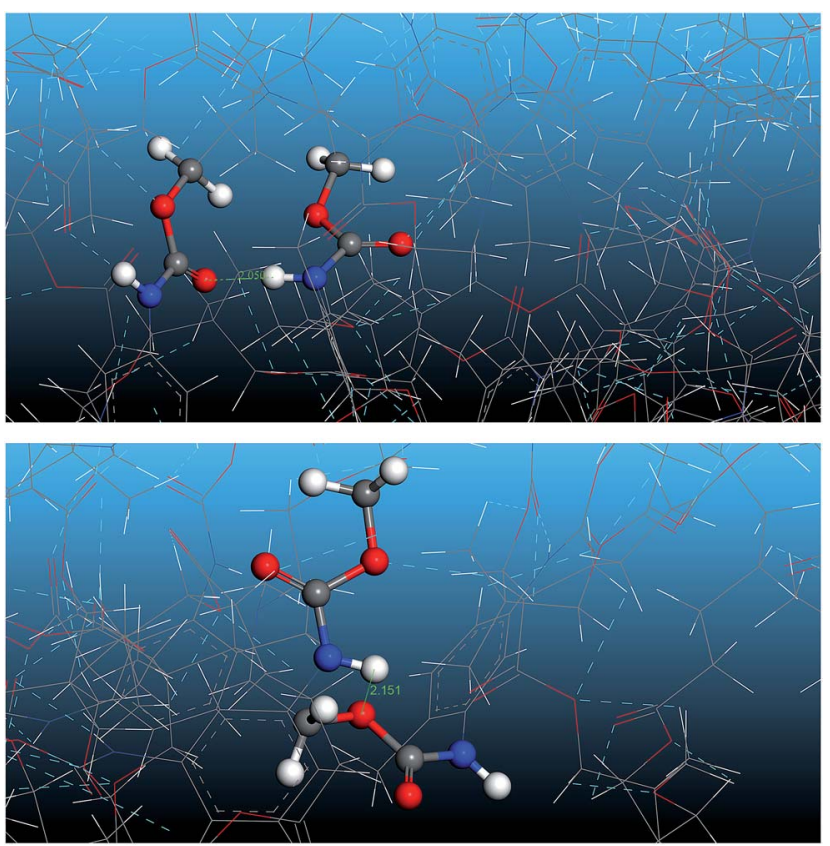

Fig. 14 Snapshot of the hydrogen bonding between urethane compounds. 

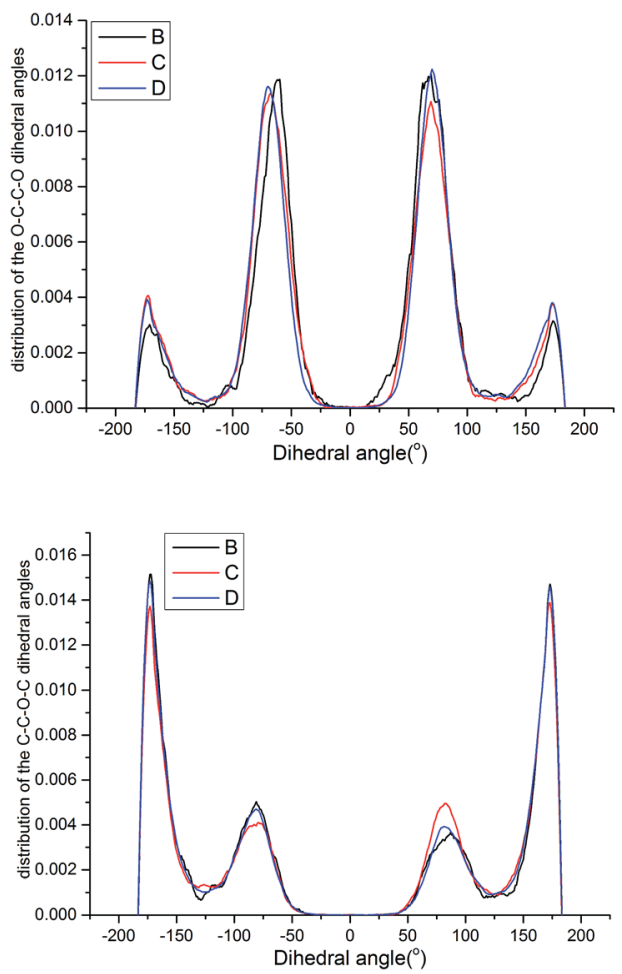

Fig. 15 Probability distribution of the dihedral torsions for the $\mathrm{O}-\mathrm{C}-$ $\mathrm{C}-\mathrm{O}$ torsion (left) and $\mathrm{C}-\mathrm{O}-\mathrm{C}-\mathrm{C}$ torsion (right) in the backbone.

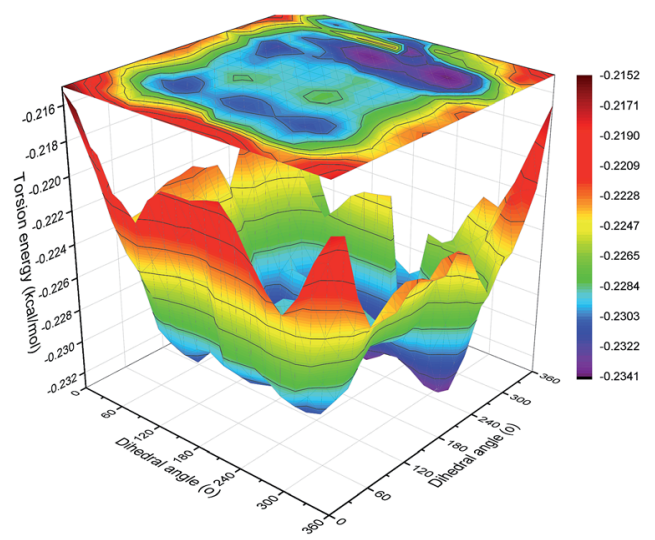

Fig. 16 Contour maps of torsion energy vs. dihedral angles $\mathrm{O}-\mathrm{C}-\mathrm{C}-$ $\mathrm{O}$ and $\mathrm{C}-\mathrm{O}-\mathrm{C}-\mathrm{C}$ in backbone.

conformation had low flexibility, whereas all the samples with a disordered, helical conformation had high flexibility.

Dihedral scans. The conformational characteristics of the polymer largely depend on the flexibility of the PEG-g in the PAE chains, which can be evaluated by the torsion energy of the double dihedral angle $\mathrm{C}-\mathrm{C}$ or $\mathrm{O}-\mathrm{C}$ groups attached to the adjacent bonds. The geometric structures were optimized with every $20^{\circ}$ rotation of the $\mathrm{C}-\mathrm{C}$ or $\mathrm{O}-\mathrm{C}$ bonds in the backbone. The upper and lower limits of the contour maps of the torsion energy were -0.215 and $-0.235 \mathrm{kcal}$, respectively (Fig. 16). It is necessary to overcome a higher energy if the molecule tends to form the all-trans configuration. From the viewpoint of the

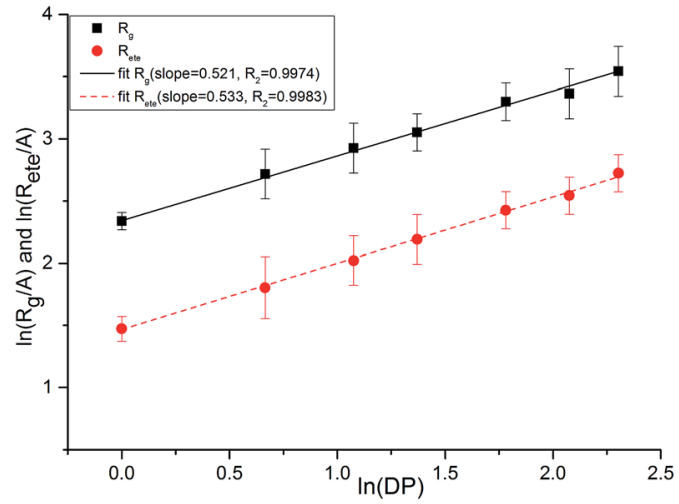

Fig. 17 Average chain end-to-end distance $\left(R_{\text {ete }}\right)$ and chain radius of gyration $\left(R_{\mathrm{g}}\right)$ as a function of DP.

energy barrier, this finding further indicates that the helical conformation is the dominant conformation.

As shown in Fig. 17, we plotted the average end-to-end distance and the average radius of gyration as a function of degree of polymerization (DP) for PEG-g on a log-log plot to verify the spatial structure of the polymer chain. We fitted these data to an equation of the form:

$$
y=A(\mathrm{DP})^{x}
$$

where $y$ is a property related to DP via the scaling exponent, $x$.

Both the structural measures could be well fitted by eqn (4). The scaling exponents for the radius of gyration and the chain end-to-end distance were 0.521 and 0.533 , respectively. These exponents are close to 0.5 , which is the scaling exponent for the characteristic polymer size in the case of sufficiently long chains, where the chains behave as random walks (RWs), as shown by Kamio et al. ${ }^{58}$ As is known, polymer chains with a scale factor higher than 0.6 can be classified as rigid chains, and the higher the scale factor, the more rigid the polymer chains. ${ }^{55}$ All of those results indicated that the increasing DP could result in a more flexible polymer chain.

\section{Conclusions}

In this work, a series of stable CWPUs with a high solid content were synthesized via the introduction of cationic groups in soft segments and in the chain terminal of polyurethanes as well as by a combination of cationic ionic and nonionic segments. We explored the synergistic effect of cation ionic (MDEA) and nonionic monomers (PAE) in polyurethane, where the dispersion size, viscosity and stability of the latex were all successfully optimized. It was found that the effect on improving the dispersibility and stability was in the order of: PEG-g-400 $\approx$ PEG-g$1000>$ PEG-g-1500 $\gg$ PEG-g-200, since the longer $\left(-\mathrm{CH}_{2}-\mathrm{CH}_{2}-\right.$ $\mathrm{O}-)_{n}$ chain with stronger hydrophilicity can enter the surface of latex particles. We also found that an appropriate diameter ratio of latex particles can increase the packing efficiency and decrease the viscosity, thus raising the upper limit of the solid content for the CWPUs. 
The highest solid content (52.18\%) CWPU was obtained by incorporation of PAE and a low terminal ions content $(2.5 \%)$, which had a bimodal particle size distribution. We then chose representative samples and were able to show that the key factors to obtain a high solids content with low viscosities is the control of the particle size and its distribution. The thermal and tensile-strength properties of films derived from CWPUs were also analyzed. The results also showed that the temperature of thermal degradation slightly increases with the increasing length of PEG-g, which can be attributed to the length of PAE increasing and the degree of phase separation decreasing at the same time also leading to lower hydrogen bonding interactions. Meanwhile, with the increment of the PEG-g length, the hydrogen bonding was weakened and the extent of phase separation decreased, resulting in the tensile strength decreasing and the elongation at break increasing.

We further discussed the structure-morphological-property relations of CWPU by using simulations based on a realistic model. The static structure and dynamic properties were analyzed. It was found that the flexibility of the chain increased (e.g. MSD, chain end-to-end distance and radius of gyration) with increasing PEG-g, which led to the number of hydrogen bonds as well as $T_{\mathrm{g}}$ decreasing. The scaling exponents for the radius of gyration and the chain end-to-end distance also illustrated that increasing the DP could result in a more flexible polymer chain. Besides, all the samples had a helical conformation, which meant that the polymer chain had large flexibility. All of these simulation results intuitively reveal the microcosmic conformation of the molecular chain, and in further detail elucidated the effect of introducing PAE on the polymer properties.

\section{Acknowledgements}

We would like to acknowledge Dr Cheng Bian for his assistance on technical details of the molecular dynamics simulation. This research was supported by HPC Platform, Xi'an Jiaotong University.

\section{References}

1 M. Furukawa, Y. Hamada and K. Kojio, J. Polym. Sci., Part B: Polym. Phys., 2003, 41, 2355-2364.

2 A. K. Nanda and D. A. Wicks, Polymer, 2006, 47, 1805-1811. 3 A. K. Nanda, D. A. Wicks, S. A. M. And and J. U. Otaigbe, Macromolecules, 2006, 39, 7037-7043.

4 K.-L. Noble, Prog. Org. Coat., 1997, 32, 131-136.

5 M. S. Yen, P. Y. Tsai and P. D. Hong, Colloids Surf., A, 2006, 279, 1-9.

6 P. Król, Prog. Mater. Sci., 2007, 52, 915-1015.

7 A. V. Raghu, G. S. Gadaginamath, S. S. Jawalkar, S. B. Halligudi and T. M. Aminabhavi, J. Polym. Sci., Part A: Polym. Chem., 2006, 44, 6032-6046.

8 J. Repáková, P. Capková, M. Studenovský and M. Ilavský, J. Mol. Model., 2004, 10, 240-249.

9 H. J. Dong, E. Y. Kim, Y. S. Kang and B. K. Kim, Colloids Surf., A, 2010, 370, 58-63.
10 S. J. Peng, Y. Jin, X. F. Cheng, T. B. Sun, R. Qi and B. Z. Fan, Prog. Org. Coat., 2015, 86, 1-10.

11 L. Hou, Y. Ding, Z. Zhang, Z. Sun and Z. Shan, Colloids Surf., A, 2015, 467, 46-56.

12 K. Burja, U. Šegedin, S. Skale, P. Berce, P. Šket, P. Prosen and D. Kukanja, Prog. Org. Coat., 2015, 78, 275-286.

13 S. J. Peng, Y. Jin, T. Sun, R. Qi, B. Z. Fan and X. F. Cheng, J. Appl. Polym. Sci., 2014, 131, 40420.

14 M. Zhang, S. T. Hemp, M. Zhang, M. H. Allen, R. N. Carmean, R. B. Moore and T. E. Long, Polym. Chem., 2014, 5, 3795-3803.

15 D. Shaw, Introduction to Colloid and Surface Chemistry, Butterworths, 4th edn, 1970.

16 P. A. Lovell and M. S. El-Aasser, Emulsion polymerization and emulsion polymers, J. Wiley, 1997.

17 I. D. F. A. Mariz, J. C. D. L. Cal and J. R. Leiza, Polymer, 2010, 51, 4044-4052.

18 R. Greenwood, P. F. Luckham and T. Gregory, Colloids Surf., A, 1998, 144, 139-147.

19 J. Meuldijk, Polym. React. Eng., 1998, 6, 243-268.

20 I. D. F. A. Mariz, J. R. Leiza and J. C. D. L. Cal, Chem. Eng. J., 2011, 168, 938-946.

21 R. Greenwood, P. F. Luckham and T. Gregory, J. Colloid Interface Sci., 1997, 191, 11-21.

22 D. Dieterich, Prog. Org. Coat., 1981, 9, 281-340.

23 S. K. Lee and B. K. Kim, J. Colloid Interface Sci., 2009, 336, 208-214.

24 Y. Chen and Y. L. Chen, J. Appl. Polym. Sci., 1992, 46, 435443.

25 B. K. Kim and Y. M. Lee, J. Appl. Polym. Sci., 1994, 54, 18091815.

26 B. K. Kim, J. S. Yang, S. M. Yoo and J. S. Lee, Colloid Polym. Sci., 2003, 281, 461-468.

27 M. Rahmati, H. Modarress and R. Gooya, Polymer, 2012, 53, 1939-1950.

28 D. Zhou and P. Choi, Polymer, 2012, 53, 3253-3260.

29 E. Yılgör, İ. Yılgör and E. Yurtsever, Polymer, 2002, 43, 65516559.

30 E. Yildirim, M. Yurtsever, G. L. Wilkes and I. Yilgör, Polymer, 2016, 90, 204-214.

31 S. Sami, E. Yildirim, M. Yurtsever, E. Yurtsever, E. Yilgor, I. Yilgor and G. L. Wilkes, Polymer, 2014, 55, 4563-4576.

32 S. Plimpton, J. Comput. Phys., 1995, 117, 1-19.

33 W. Humphrey, A. Dalke and K. Schulten, J. Mol. Graphics, 1996, 14, 33-38.

34 S. L. Mayo, B. D. Olafson and W. A. Goddard, J. Phys. Chem., 1990, 94, 8897-8909.

35 L. Verlet, Phys. Rev., 1967, 159, 98.

36 L. Verlet, Phys. Rev., 1968, 165, 201.

37 J. Eastwood, R. Hockney and D. Lawrence, Comput. Phys. Commun., 1980, 19, 215-261.

38 H. J. Berendsen, J. V. Postma, W. F. van Gunsteren, A. DiNola and J. Haak, J. Chem. Phys., 1984, 81, 3684-3690.

39 M. J. Frisch, G. W. Trucks, H. B. Schlegel, G. E. Scuseria, M. A. Robb, J. R. Cheeseman, G. Scalmani, V. Barone, B. Mennucci, G. A. Petersson, H. Nakatsuji, M. Caricato, X. Li, H. P. Hratchian, A. F. Izmaylov, J. Bloino, G. Zheng, 
J. L. Sonnenberg, M. Hada, M. Ehara, K. Toyota, R. Fukuda, J. Hasegawa, M. Ishida, T. Nakajima, Y. Honda, O. Kitao, H. Nakai, T. Vreven, J. A. Montgomery Jr, J. E. Peralta, F. Ogliaro, M. J. Bearpark, J. Heyd, E. N. Brothers, K. N. Kudin, V. N. Staroverov, R. Kobayashi, J. Normand, K. Raghavachari, A. P. Rendell, J. C. Burant, S. S. Iyengar, J. Tomasi, M. Cossi, N. Rega, N. J. Millam, M. Klene, J. E. Knox, J. B. Cross, V. Bakken, C. Adamo, J. Jaramillo, R. Gomperts, R. E. Stratmann, O. Yazyev, A. J. Austin, R. Cammi, C. Pomelli, J. W. Ochterski, R. L. Martin, K. Morokuma, V. G. Zakrzewski, G. A. Voth, P. Salvador, J. J. Dannenberg, S. Dapprich, A. D. Daniels, Ö. Farkas, J. B. Foresman, J. V. Ortiz, J. Cioslowski and D. J. Fox, Gaussian 09, Revision A.02., Gaussian Inc., Wallingford, CT, 2009.

40 A. D. Becke, Phys. Rev. A, 1988, 38, 3098-3100.

41 C. Lee, W. Yang and R. G. Parr, Phys. Rev. B: Condens. Matter Mater. Phys., 1988, 37, 785-789.

42 P. Stephens, F. Devlin, C. Chabalowski and M. J. Frisch, J. Phys. Chem., 1994, 98, 11623-11627.

43 S. Grimme, J. Antony, S. Ehrlich and H. Krieg, J. Chem. Phys., 2010, 132, 154104.

44 K. Dong, Y. Cao, Q. Yang, S. Zhang, H. Xing and Q. Ren, Ind. Eng. Chem. Res., 2012, 51, 5299-5308.
45 L. Liu, X. Wu and T. Li, J. Power Sources, 2014, 249, 397-404. 46 L. F. Wang, Q. Ji, T. E. Glass, T. C. Ward, J. E. Mcgrath, M. Muggli, G. Burns and U. Sorathia, Polymer, 2000, 41, 5083-5093.

47 H. Oh and P. F. Green, Nat. Mater., 2009, 8, 139-143.

48 F. Khabaz and R. Khare, J. Phys. Chem. B, 2015, 119, 1426114269.

49 D. Qi, J. Hinkley and G. He, Modell. Simul. Mater. Sci. Eng., 2005, 13, 421-433.

50 F. Pan, J. Ma, L. Cui and Z. Jiang, Chem. Eng. Sci., 2009, 64, 5192-5197.

51 A. Shrake and J. Rupley, J. Mol. Biol., 1973, 79, 351-371.

52 E. Yildirim and M. Yurtsever, Comput. Theor. Chem., 2014, 1035, 28-38.

53 C. Wu and W. Xu, Polymer, 2007, 48, 5802-5812.

54 T. Steiner, Angew. Chem., Int. Ed., 2002, 41, 48-76.

55 C. Bian, S. Wang, Y. Liu, K. Su and X. Jing, Ind. Eng. Chem. Res., 2016, 55, 9440-9451.

56 J. Zheng, L. Li, H. K. Tsao, Y. J. Sheng, S. Chen and S. Jiang, Biophys. J., 2005, 89, 158-166.

57 P. Bačová, A. N. Rissanou and V. Harmandaris, Macromolecules, 2015, 48, 1577-1586.

58 K. Kamio, K. Moorthi and D. N. Theodorou, Macromolecules, 2007, 40, 710-722. 